\title{
Use of dermoscopy in the diagnosis of temporal triangular alopecia*
}

\author{
Jullyene Gomes de Campos ${ }^{1}$ \\ Cláudia Marina Puga Barbosa Oliveira ${ }^{1}$ \\ Sandra Adolfina Reyes Romero ${ }^{1,2}$
}

\author{
Ana Paula Klein ${ }^{1}$ \\ Patricia Bandeira de Melo Akel ${ }^{1}$ \\ Giselle Martins Pinto ${ }^{3}$
}

Abstract: Temporal triangular alopecia, also referred as congenital triangular alopecia, is an uncommon dermatosis of unknown etiology. It is characterized by a non-scarring, circumscribed alopecia often located unilaterally in the frontotemporal region. It usually emerges at ages 2-9 years. Alopecia areata is the main differential diagnosis, especially in atypical cases. Dermoscopy is a noninvasive procedure that helps distinguish temporal triangular alopecia from aloepecia areata. Such procedure prevents invasive diagnostic methods as well as ineffective treatments.

Keywords: Alopecia; Dermoscopy; Diagnosis

\section{INTRODUCTION}

Temporal triangular alopecia (TTA), also called congenital triangular alopecia, was first described by Sabouraud in 1905 as "alopecia triangulaire congenitale de la temp" ${ }^{1,2,3}$ The term congenital triangular alopecia has become inadequate because most cases arise at ages 2-9 years and the disease may even manifest itself in adulthood. .,3,4 $^{-1}$

TTA is an uncommon dermatosis of unknown etiology. It usually emerges sporadically. Reports of familial cases suggest the presence of a para-dominant inheritance. ${ }^{3,5}$ It is also postulated that TTA may be related to mosaicism. Autosomal dominant inheritance is possibly present in cases associated with syndromes. ${ }^{2,5,6}$

TTA is clinically characterized by a rounded, oval, triangular or more commonly spear-shaped area of alopecia located in the frontotemporal region. ${ }^{2,45}$

The main differential diagnoses are alopecia areata, trichotillomania, traction alopecia and congenital aplasia cutis. ${ }^{4}$ Many cases of TTA are diagnosed and treated as alopecia areata, especially when the area of alopecia occurs outside its usual location or when it arises at a later stage..$^{4,5}$
Thus, scalp dermoscopy is an indispensable tool for a correct diagnosis. ${ }^{2,4}$ Its use reduces the need for invasive diagnostic procedures and avoids unnecessary treatments.

\section{CASE REPORT}

A three-month-old girl presented an area of alopecia in the right temporal region from birth. Physical examination revealed a well-demarcated, spear-shaped area of alopecia measuring $4.0 \times 1.5 \mathrm{~cm}$ (Figure 1). The overlying skin was normal (absence of atrophy, desquamation or inflammation). Dermoscopy (DermLite I; 3Gen) revealed normal follicular openings with vellus hairs surrounded by the terminal hairs (Figure 2). The child's parents denied the occurrence of previous traumatic events and having similar cases in the family. After clinical and dermoscopic diagnosis, the parents were reassured about the benign nature of the disease, and decided together with the physician for an expectant management of the disease.

\footnotetext{
Received on 21.04.2014.

Approved by the Advisory Board and accepted for publication on 23.06.2014.

* Study conducted at the Dermatology Service of the Hospital Universitário Getúlio Vargas - Universidade Federal do Amazonas (HUGV-UFAM) Manaus (AM), Brazil.

Conflict of interest: None

Financial funding: None

Universidade Federal do Amazonas (UFAM) - Manaus (AM), Brazil

Fundação de Medicina Tropical Doutor Heitor Vieira Dourado (FMTHVD) - Manaus (AM), Brazil.

Santa Casa de Misericórdia de Porto Alegre - Porto Alegre (RS), Brazil. 


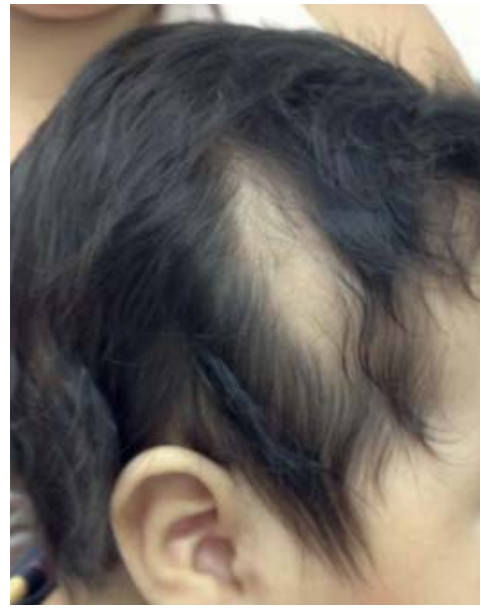

FIGURE 1:

Clinical examination: non-scarring, spear-shaped area of alopecia. No signs of inflammation. No changes in consistency or appearance of the overlying skin

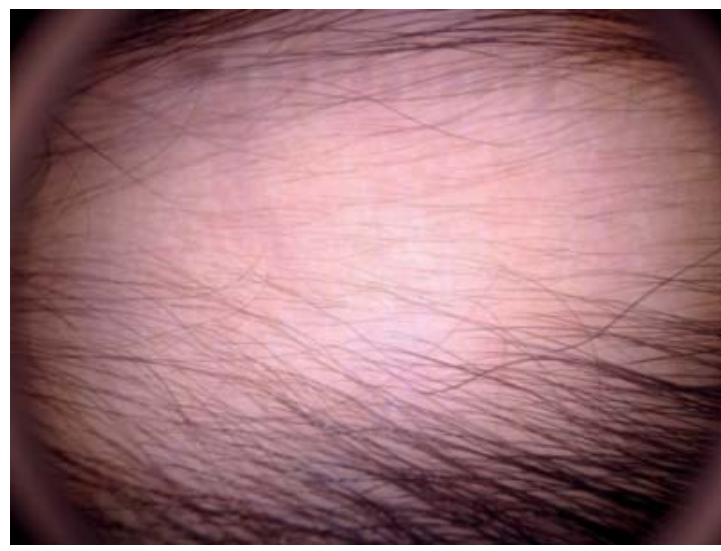

FIGURE 2: Dermoscopy: normal follicular openings with vellus hairs surrounded by terminal hairs on the outskirts of the lesion; absence of yellow and/or black dots, brittle hair and 'exclamation mark' hairs

\section{DISCUSSION}

TTA is a non-inflammatory and non-scarring form of alopecia that remains stable throughout life..$^{2,3,4}$

It is described by many authors as a rare dermatosis. ${ }^{2}$ Its incidence has been estimated at $0.11 \%$ by Hernandes et al. ${ }^{2}$ However, it is believed that TTA is a common but underdiagnosed disorder, because only a few affected persons seek medical care and many patients are misdiagnosed. ${ }^{4,7}$

In most cases, TTA becomes clinically evident between ages 2 and 9 years. ${ }^{2,4,7}$ It may occur at birth or later during adulthood. ${ }^{8}$ TTA affects mainly white patients and both sexes are equally affected. ${ }^{3,4}$ The area of alopecia is usually asymptomatic, but some patients report dysesthesia. ${ }^{4}$

TTA manifests itself as a spear-shaped, oval, round or triangular area of alopecia unilaterally locat- ed in the frontotemporal region. ${ }^{2,4}$ It may affect other areas of the scalp - including the occipital region - and it may also be bilateral. ${ }^{9}$ Sometimes there is a small fringe with terminal hairs at the front edge of the lesion and even a tuft of hair at the center of the lesion. $.3,6$

Some diseases have been associated with TTA, such as: Down syndrome, iris nevus syndrome, phakomatosis pigmentovascularis, congenital heart disease, bone and tooth abnormalities, mental retardation and congenital aplasia cutis. ${ }^{6,10}$

Histopathology shows a normal number of follicles with a predominance of vellus hairs and rare terminal hairs on the superficial dermis.,4 Inflammatory and/or scarring processes are not observed.

Alopecia areata is the main differential diagnosis of TTA. ${ }^{2,45}$ Dermoscopy helps differentiate between these two diseases, avoiding the performance of biopsies to confirm the diagnosis. ${ }^{4,5}$ Dermoscopic findings include normal follicular openings with vellus hairs covering the area of alopecia and terminal hairs on the outskirts of the lesion. ${ }^{4}$ Black and/or yellow dots and 'exclamation mark' hairs, which are present in alopecia areata, are absent in this dermatosis., ${ }^{2,4}$

In a study conducted by Inui et al in 2011, the authors stressed the importance of the diagnostic criteria of TTA and proposed the following criteria: I) triangular or spear-shaped area of alopecia involving the frontotemporal region of the scalp; II) dermoscopy reveals normal follicular openings with vellus hairs surrounded by normal terminal hair; III) dermoscopy shows absence of yellow and black spots, dystrophic hairs, and decreased follicular openings; IV) persistence of no significant hair growth after dermoscopic and clinical confirmation of the existence of vellus hairs. ${ }^{4}$

There is no effective treatment for TTA and, in most cases, there is no need for therapeutic intervention. ${ }^{2,78}$ Enlightening the parents about the benign nature of this dermatosis is essential. Hair implant and surgical excision of the lesion are the main therapeutic proposals in cases with significant aesthetic and emotional injury. ${ }^{78,9,10}$ Surgical exeresis is limited to cases with small areas of alopecia. Hair implant is considered by some authors to be the first-line treatment for TTA. Studies show the effectiveness and good cosmetic outcomes obtained by using this treatment modality. However, further studies with long follow-up periods need to be conducted. ${ }^{78,10}$ Bang et al. described the first successful case using topical minoxidil. Nevertheless, there is no scientific evidence confirming the efficacy of such treatment. ${ }^{7.8}$

Dermoscopy is a noninvasive tool that aids in the differential diagnosis of TTA. ${ }^{4}$ This method avoids invasive diagnostic procedures and ineffective treatments. $^{2,4} \square$ 


\section{REFERENCES}

1. Pereira JM. Congenital triangular alopecia occurring in sisters. An Bras Dermatol. 2001;76:695-700.

2. Yamazaki M, Irisawa $\mathrm{R}$, Tsuboi R. Temporal triangular alopecia and a review of 52 past cases. J Dermatol. 2010;37:360-2

3. Assouly P, Happle R. A hairy paradox: congenital triangular alopecia with a central hair tuft. Dermatology. 2010;221:107-9.

4. Inui S, Nakajima T, Itami S. Temporal triangular alopecia: trichoscopic diagnosis. J Dermatol. 2012;39:572-4.

5. Taş B, Pilanci Ö, Başaran K. Congenital temporal triangular alopecia: a typical Brauer nevus. Acta Dermatovenerol Alp Pannonica Adriat. 2013;22:93-4.

6. Lederer D, Wilson B, Lefesvre P, Poorten V, Kirkham N, Mitra D, et al. Atypical findings in three patients with Pai syndrome and literature review. Am J Med Genet A. 2012;158A:2899-904.

7. Bang CY, Byun JW, Kang MJ, Yang BH, Song HJ, Shin J, et al. Successful treatment of temporal triangular alopecia with topical minoxidil. Ann Dermatol. 2013;25:387-8.

8. Chung J, Sim JH, Gye J, Namkoong S, Hong SP, Kim MH, et al. Successful hair transplantation for treatment of acquired temporal triangular alopecia. Dermatol Surg. 2012;38:1404-6.

9. Sarifakioglu E, Yilmaz AE, Gorpelioglu C, Orun E. Prevalence of scalp disorders and hair loss in children. Cutis. 2012;90:225-9.

10. Unger R, Alsufyani MA. Bilateral Temporal Triangular Alopecia Associated with Phakomatosis Pigmentovascularis Type IV Successfully Treated with Follicular Unit Transplantation. Case Rep Dermatol Med. 2011;2011:129541.
MAILING ADDRESS:

Jullyene Gomes de Campos

Avenida Apurinã, 4. - Praça 14 de Janeiro

69020-170 - Manaus - AM

Brazil

E-mail: jullyenegomes@hotmail.com

How to cite this article: Campos JG, Klein AP, Puga C, Akel PBM, Romero SAR, Pinto GM. Use of dermoscopy in the diagnosis of temporal triangular alopecia. An Bras Dermatol. 2015;90(1):123-5. 